\title{
Identification and antimicrobial susceptibility of Staphylococcus from home- treated peritoneal dialysis patients
}

\author{
Batalha JEN (1, 2), Cunha MLRS (2), Montelli AC (1), Barreti P (1), Caramori JCT (1)
}

(1) Department of Internal Medicine, Botucatu Medical School, São Paulo State University (UNESP - Univ Estadual Paulista), Botucatu, São Paulo State, Brazil; (2) Department of Microbiology and Immunology, Botucatu Biosciences Institute, São Paulo State University (UNESP - Univ Estadual Paulista), Botucatu, São Paulo State, Brazil.

ABSTRACT: Staphylococcus aureus is the main agent of infections during peritoneal dialysis (PD). The presence of $S$. aureus in the nasal cavity has been extensively studied and suggested as a risk factor of dialysis-related infections, whereas coagulase-negative Staphylococcus (CNS) species are frequently considered part of the normal human microbiota. The aim of this study was to identify Staphylococcus in the nasal cavity, pericatheter skin and peritoneal effluent from PD patients, as well as to evaluate the antimicrobial activity evolution in vitro. Thirty-two chronic PD patients were observed during 12 months and had nasal and pericatheter skin samples collected for culture. When peritonitis was detected, samples were also collected from the peritoneal effluent for culture. The activity of several antimicrobial drugs (penicillin G, oxacillin, cephalothin, ofloxacin, netilmicin and vancomycin) against different Staphylococcus species was measured by using the agar drug diffusion assay (Kirby-Bauer method). Staphylococcus was separated into S. aureus, S. epidermidis and other CNS species in order to determine the in vitro resistance level. $S$. epidermidis resistance to oxacillin progressively increased during the study period $(p<0.05)$. Resistance to ofloxacin was inexpressive, whereas resistance to netilmicin and vancomycin was not detected. Of the oxacillin-resistant species ( $n=74), 83 \%$ were S. epidermidis, $13 \%$ other CNS and $4 \%$ S. aureus $(p<0.05)$. Regarding multidrug resistant strains ( $n=45$ ), $82 \%$ were $S$. epidermidis, $13 \%$ other CNS, and $5 \%$ S. aureus $(p<0.05)$. This study shows the relevance of resistance to oxacillin and CNS multi-drug resistance, particularly concerning $S$. epidermidis, in PD patients.

KEY WORDS: peritoneal dialysis (PD), peritonitis, risk factor, Staphylococcus, coagulase-negative Staphylococcus (CNS).

CONFLICTS OF INTEREST: There is no conflict.

\section{CORRESPONDENCE TO:}

MARIA DE LOURDES RIBEIRO DE SOUZA DA CUNHA, Departamento de Microbiologia e Imunologia, Instituto de Biociências, UNESP, Caixa Postal 510, Botucatu, SP, 18.618-000, Brasil. Phone: +55 1438116058 . Email: cunhamlr@ibb.unesp.br. 


\section{INTRODUCTION}

Staphylococcus species represent the most frequent cause of infection in home peritoneal dialysis (PD). In Brazil, during the two first decades of home PD, S. aureus was considered the main cause of peritonitis (1-4). However, recent Brazilian data, similarly to those reported in the literature, have demonstrated that coagulasenegative Staphylococcus (CNS) species are the main etiological agents of these infections (4-7).

Staphylococcus is subdivided into forty species and most of them are coagulasenegative. Nevertheless, the capacity of enzyme synthesis is reserved to $S$. aureus, $S$. schleiferi subspecies coagulans, S. intermedius, S. hyicus and S. delphini $(8,9)$.

Nasal carriers of $S$. aureus have been extensively studied by several authors and the presence of this bacterium in the nasal cavity has been pointed out as a major risk factor of dialysis-related infections, although a reduction in peritonitis has been reported (10-18). CNS is considered part of the normal microbiota in humans; still, it is recognized as a cause of infections of variable severity. Tzamaloukas (19) reported that CNS infections evolved without severe consequences, presenting benign characteristics, whereas other authors have described a different bacterial profile, observing significant levels of recurrent peritonitis $(20,21)$.

According to Berns (22), the behavior of CNS strains can be similar to that of $S$. aureus, i.e. resistant to methicillin and other $\beta$-lactam antimicrobials such as cephalosporins and carbapenems. Therefore, detailed microbiological studies on these species are of high importance for the prognosis and treatment of peritonitis. The present investigation also aimed to identify Staphylococcus species and characterize the evolution of its resistance to oxacillin and other drugs in nasal cavity, pericatheter skin and peritoneal effluent samples from patients undergoing PD.

\section{PATIENTS AND METHODS}

This study included patients undergoing peritoneal dialysis (manual or automated) and was conducted from January 2003 to July 2004 in the Botucatu Medical School, São Paulo State University (UNESP - Univ Estadual Paulista), Brazil. Patients without episodes of associated peritonitis in the previous three months and not receiving antibiotics in the previous month were included. Patients who did not follow the protocol were excluded from the trial to avoid lack of feedback. The included patients were followed for a minimum period of 12 months and information about 
their age, gender, race, diabetes, PD and treatment length was recorded. Sterile swabs were used to collect nasal and pericatheter skin samples. Samplings were done at the beginning of the trial, after two months and between nine and 12 months after the first collection.

Peritonitis was defined as the emergence of unclear peritoneal effluent, followed or not by abdominal pain, painful and abrupt abdominal decompression, nausea, vomiting and fever. The infection was confirmed by a leukocyte count in dialysis effluent greater than 100 cells $/ \mathrm{mm}^{3}$, in the presence of polymorphonuclear cells. Cultures were prepared by aseptically collecting $40 \mathrm{~mL}$ of peritoneal effluent from the

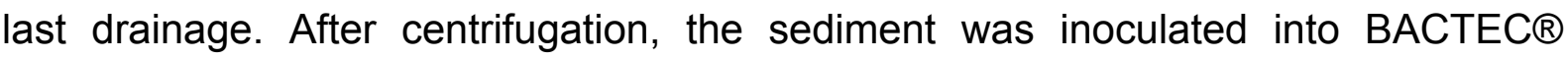
bottles (BD, USA). For microbial identification, colonies were gram-stained. Staphylococcus was differentiated from Micrococcus throughout glucose oxidation and fermentation, bacitracin resistance $(0.04 \mathrm{U})$ and sensitivity to furazolidone (100 $\mu g)$. Coagulase test was employed to differentiate $S$. aureus from CNS (23). The latter was identified by using the simplified method proposed by Cunha et al. (24) through analysis of sugar utilization, lactose, anaerobic growth in thioglycollate broth, nitrate reduction, hemolysins, urease and ornithine decarboxylase.

Sensitivity test to antimicrobial drugs was carried out by means of agar drug diffusion assay (Kirby-Bauer method), as recommended by the Clinical Laboratory Standard Institute (CLSI) (25). The employed disks were: penicillin G (10 UI), oxacillin (1 $\mu \mathrm{g})$, cephalothin $(30 \mu \mathrm{g})$, netilmicin $(30 \mu \mathrm{g})$, ofloxacin $(5 \mu \mathrm{g})$ and vancomycin $(30 \mu \mathrm{g})$ purchased from CECON (Brazil). Sensitivity, drug resistance and control test based on international reference strains (ATCC 25923) followed the CLSI recommendations (25).

Evaluations were performed by separating the strains from the different sites into three groups: S. aureus, S. epidermidis and other CNS. We verified the proportion of strains resistant to six drugs (in three evolutional samples), the resistance to oxacillin in all three groups of Staphylococcus, and the frequency of multi-drug resistant strains (microbial resistance to more than one tested drug). Considering that six drugs were tested, resistance to oxacillin and cephalothin was interpreted as a single resistance. 


\section{Statistical analysis}

To compare frequencies, chi-square test was employed. For the tested hypothesis, $p$ $<0.05$ was considered significant.

\section{RESULTS}

The characteristics of the 32 patients studied are shown in Table 1. Their mean age was $54.7 \pm 17$ years (between 21 and 85 years); $62.5 \%$ patients $(n=20)$ were male; $40.6 \%(n=13)$ diabetic; white color prevailed among $84.4 \%(n=27)$ and manual dialysis among $75 \%$ patients. Dialysis mean length was $34.6 \pm 20$ months.

Ninety-six nasal and pericatheter skin samples were collected from thirty-two PD patients; when peritonitis was diagnosed, peritoneal effluent samples were also obtained. The research resulted in the identification of 288 Staphylococcus strains, 155 from the nasal cavity, 122 from skin and 11 from the peritoneal effluent. The frequency of identified species was $21.9 \%$ S. aureus and $78.1 \%$ CNS (Table 2). In the nasal cavity, CNS species were predominant, representing $78.7 \%$, with $50.3 \%$ S. epidermidis, $13.5 \%$ S. warneri and $7.1 \%$ S. haemolyticus. The isolated S. aureus strains accounted for $21.3 \%$. In the pericatheter skin, the distribution was similar; $22.1 \%$ S. aureus and $77.9 \%$ CNS were isolated, while the most frequent were: $50.0 \%$ S. epidermidis, $10.6 \%$ S. haemolyctius and $9.0 \%$ S. warneri. In the 11 cases of peritonitis, the distribution percentage of Staphylococcus species was similar to that found in the extra-peritoneal sites; $72.7 \%$ CNS were isolated, $54.5 \%$ were $S$. epidermidis and $18.2 \%$ were S. warneri. In addition, $27.3 \%$ of the peritonitis cases were caused by $S$. aureus. 
Table 1. Characteristics of the 32 patients subjected to peritoneal dialysis at home

\begin{tabular}{lll}
\hline & Number & Percentage (\%) \\
\hline Age & & \\
Average in years & $54.7 \pm 17$ & \\
\hline Gender & 20 & 62.5 \\
Male & 12 & 37.5 \\
Female & & \\
\hline Color & 27 & $84.4^{*}$ \\
White & 5 & 15.6 \\
Nonwhite & & \\
Diabetes mellitus & 13 & 40.6 \\
Yes & 19 & 59.4 \\
No & & \\
\hline Dialysis method & 24 & $75^{*}$ \\
Manual & 8 & 25 \\
Automated & & \\
\hline
\end{tabular}

${ }^{*} p<0.05$.

Table 2. Distribution of Staphylococcus isolated from the nasal cavity, pericatheter skin and peritoneal effluent

\begin{tabular}{c|c|c|c|c}
\hline Species & \multicolumn{4}{|c}{ Sampling site } \\
\hline & $\begin{array}{c}\text { Nasal cavity \% } \\
\text { (n) }\end{array}$ & $\begin{array}{c}\text { Pericatheter skin \% } \\
(\mathbf{n})\end{array}$ & $\begin{array}{c}\text { Peritoneal effluent } \\
\%(\mathbf{n})\end{array}$ & Total \\
\hline S. aureus & $21.3(33)$ & $22.1(27)$ & $27.3(3)$ & 63 \\
\hline S. epidermidis & $50.3(78)$ & $50.0(61)$ & $54.5(6)$ & 145 \\
\hline S. warneri & $13.5(21)$ & $9.0(11)$ & $18.2(2)$ & 34 \\
\hline S. haemolyticus & $7.1(11)$ & $10.6(13)$ & 0 & 24 \\
\hline S. saprophyticus & $2.6(4)$ & $1.6(2)$ & 0 & 6 \\
\hline S. capitis & $1.9(3)$ & $1.6(2)$ & 0 & 5 \\
\hline S. simulans & $1.9(3)$ & $1.6(2)$ & 0 & 5 \\
\hline S. lugdunensis & $0.6(1)$ & $1.6(2)$ & 0 & 3 \\
\hline S. hominis & 0 & $1.6(2)$ & 0 & 2 \\
\hline S. schleiferi & $0.6(1)$ & 0 & 0 & 1 \\
\hline Total & 155 & 122 & 11 & 288 \\
\hline
\end{tabular}

The in vitro antimicrobial resistance profile of Staphylococcus strains to the six studied drugs was done for all samples obtained in the three collections. The percentage of penicillin G-resistant strains did not vary during the collection, including around $80 \%$ S. epidermidis, $60 \%$ other CNS and $70 \%$ S. aureus. As to the in vitro activity of oxacillin (Figure 1), resistant S. epidermidis strains accounted for $17.3 \%$ (n 
$=9)$ in the first collection, $26.5 \%$ in the second and $44.7 \%(n=17)$ in the third sampling. The increasing rates of oxacillin resistance were statistically significant $(p<$ 0.05); for other Staphylococcus species, resistance results did not differ. The in vitro resistance to cephalothin was inexpressive among Staphylococcus species: $1.9 \%$ (n $=1$ ) for $S$. epidermidis, $10 \%(n=2)$ for $S$. aureus, and no resistant for other CNS strains. In vitro resistance to ofloxacin during the studied period was $18 \%$ for $S$. epidermidis, $12 \%$ for other CNS and $7 \%$ for S. aureus. No Staphylococcus sample showed in vitro resistance to netilmicin and vancomycin.

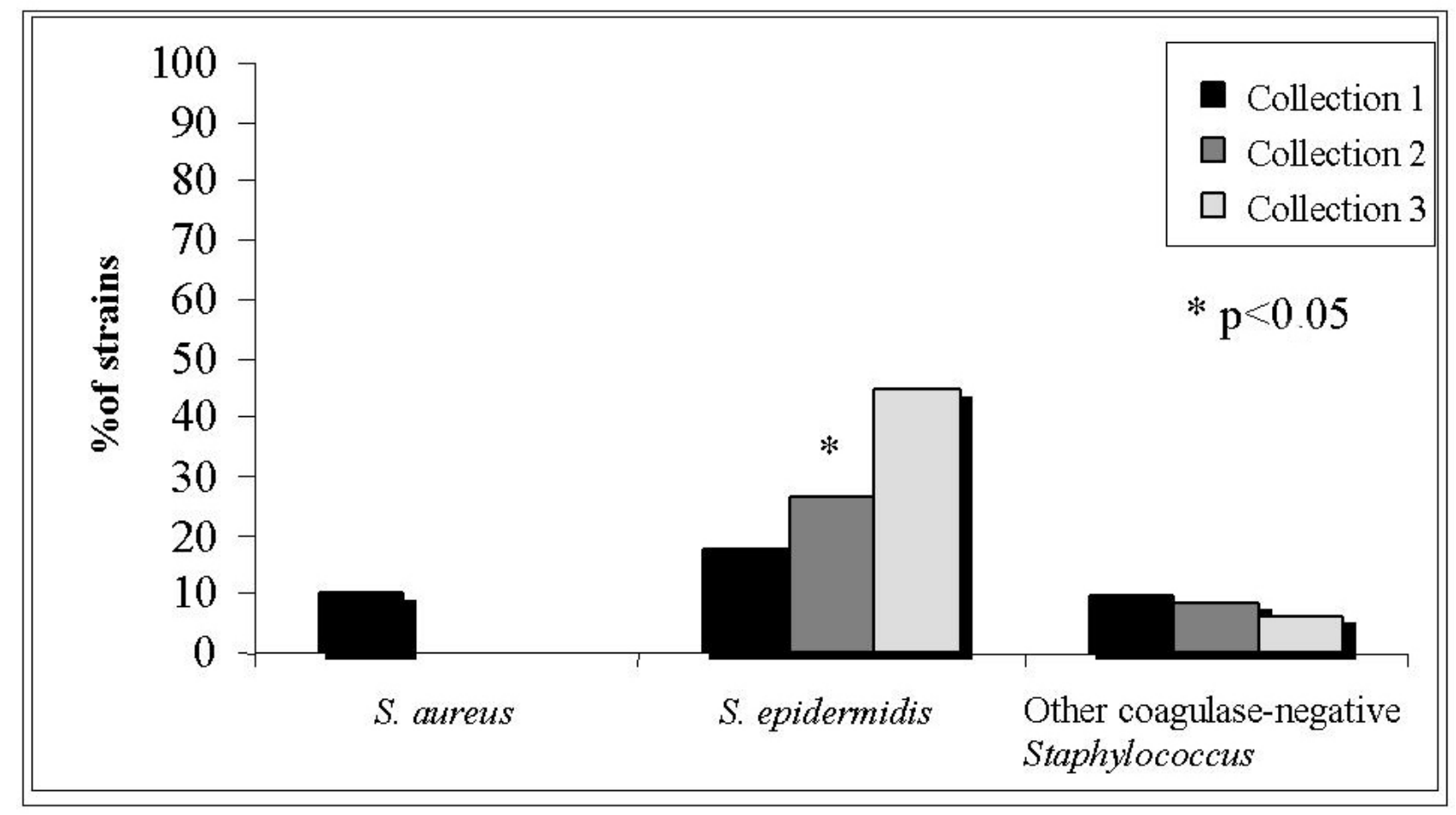

Figure 1. In vitro resistance profile of $S$. aureus, $S$. epidermidis and other CNS strains to oxacillin in three sample collections from 32 patients subjected to peritoneal dialysis at home.

The distribution of Staphylococcus species resistant to oxacillin $(n=47)$ or presenting a multi-drug resistance pattern $(n=45)$ is shown in Figure 2. Concerning strains resistant to oxacillin, $83 \%(n=39)$ were S. epidermidis, $13 \%(n=6)$ other CNS and $4 \%(n=2) S$. aureus $(p<0.05)$. Multi-drug resistance was found among $82 \% S$. epidermidis strains, $13 \%(n=6)$ other CNS and $5 \%(n=2)$ S. aureus $(p<0.05)$. 


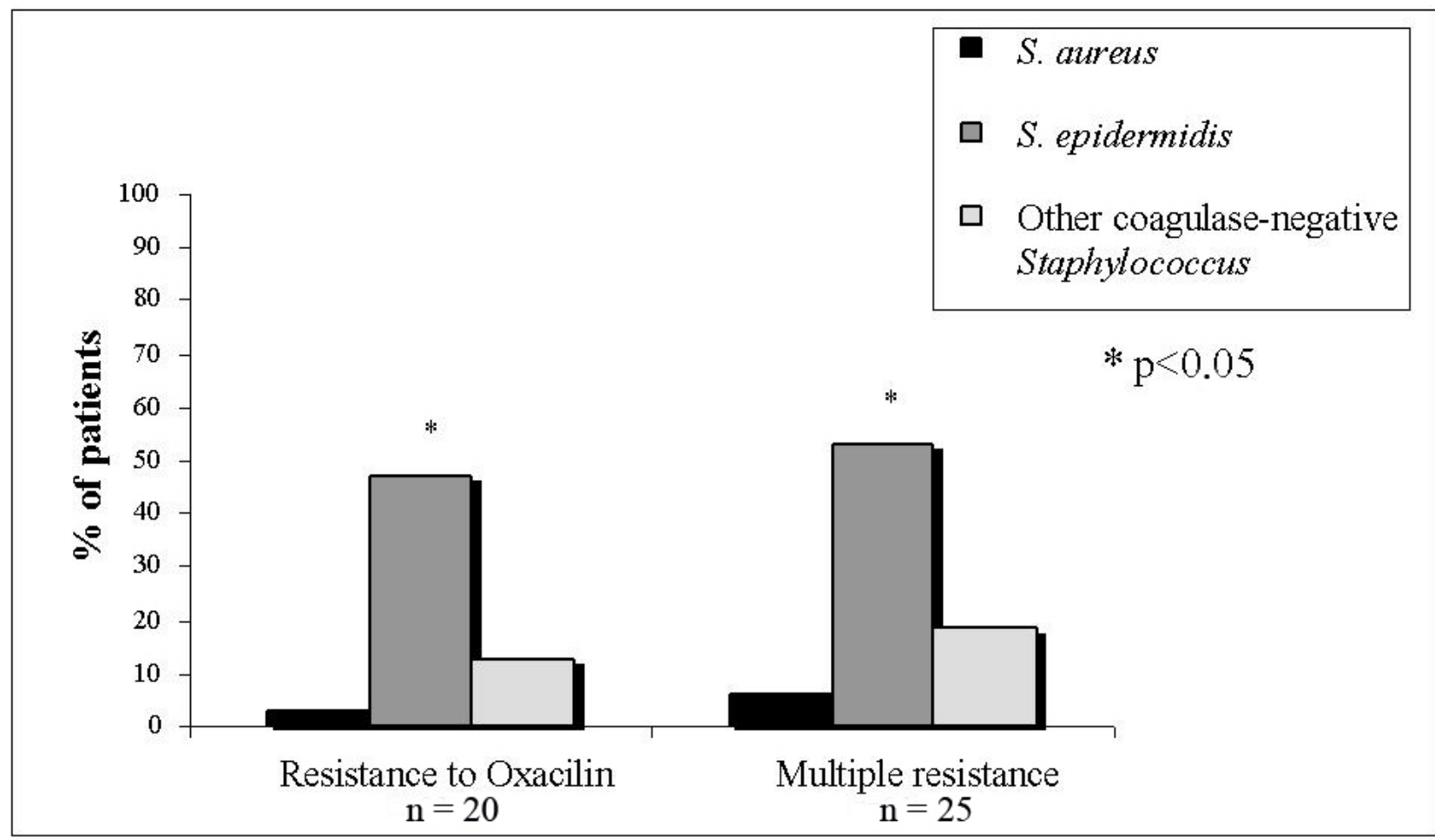

Figure 2. Frequency of oxacillin-resistant Staphylococcus and in vitro multi-drug resistance among 32 patients subjected to peritoneal dialysis at home.

\section{DISCUSSION}

The pathogens most commonly associated with peritonitis in PD patients are Staphylococcus species. The presence of $S$. aureus in nasal cavity and pericatheter skin represents a risk factor for the development of peritonitis $(14,16,26)$. However, in CNS-related peritonitis, the relationship between the presence of these microorganisms in the patients' skin and nasal cavity and the development of subsequent infection is not discussed since the related species are understood to be part of the normal microbiota.

In this investigation, we found a wide variety of Staphylococcus species in the nasal cavity, pericatheter skin and peritoneal effluent samples. The most frequent Staphylococcus species were S. epidermidis, S. aureus, S. warneri and S. haemolyticus. Due to the lack of CNS species identification in routine patients, few studies present data related to CNS in PD patients.

Eisenberg et al. (6) studied the catheter skin and nasal cavity of PD patients and reported the importance of CNS colonization, including the relevance of $S$. epidermidis as a cause of peritonitis. In the present study, similar results were found for CNS species in three collections with serial cultures. The proportional distribution 
of species among different anatomic sites suggests that there is bacterial propagation from the natural habitat to the peritoneal effluent. Considering the in vitro antimicrobial activity of oxacillin, S. epidermidis had increasing resistance during the observation period. This bacterium also presented the highest frequency of strains resistant to oxacillin, as well as multi-resistance against two or more drugs, possibly due to its mechanism of acquiring resistance from another agent or due to the in vitro selection of resistant strains (22). Some authors point out that this microorganism is the reservoir of various resistance genes, since it is the main component of skin and mucosal microbiota and is, therefore, subjected to a more selective pressure by commonly used antimicrobials. These results show that, in addition to the epidemiological importance, the identification of Staphylococcus species contributes to information on their correlation to the pathogenic potential and the sensitivity profile of antimicrobials (6).

The in vitro antimicrobial activity of cephalothin resulted in few resistant strains in all three samplings and, according to CLSI (25), Staphylococcus strains resistant to methicillin and oxacillin are also resistant to cephalosporin. Thus, their sensitivity must not be assessed in vitro, since laboratory tests not always represent the interaction between the pathogen and the antibiotic in vivo. Zelenitsky et al. (27) reported limitations of in vitro sensitivity tests for peritonitis treatment in PD, since the tolerance to the antibiotic by the bacteria isolated from the peritoneal effluent differed from that obtained in standard medium, suggesting that growth conditions are important factors in the acquisition of bacterial tolerance.

Nouwen et al. (16) showed that persistent $S$. aureus nasal carriers did not present resistance to vancomycin, and $2 \%$ of the CNS strains isolated from the same site revealed intermediate resistance to that drug.

The results obtained in the present study reinforce the importance of recognizing endogenous sources of different Staphylococcus species and their in vitro susceptibility in the prognosis and treatment of peritonitis $(6,16)$. Although the isolation of CNS species by means of molecular techniques is complex, it will establish colonization patterns and allow advances in the prevention of infections caused by these species. 


\section{REFERENCES}

1. Sesso R, Draibe S, Castelo A, Sato I, Leme I, Barbosa D, et al. Staphylococcus aureus skin carriage and development of peritonitis in patients on continuous ambulatory peritoneal dialysis. Clin Nephrol. 1989;31(5):264-8.

2. Bevilacqua JL, Marabezi MGB, Caniello CA, Camargo MC, Neves AV, Gomes JG. Diálise peritoneal contínua ambulatorial (DPAC): experiência de 10 anos de um centro brasileiro. J Bras Nefrol. 1995;17(4):206-13.

3. Caramori JCT. Peritonites em pacientes tratados com diálise peritoneal ambulatorial contínua: estudo clínico e microbiológico [thesis]. Botucatu: Faculdade de Medicina, Universidade Estadual Paulista; 1999.

4. Pecoits-Filho RFS, Pasqual DD, Fuerbringer R, Sauthier SM, Riella MC. Diálise peritoneal contínua ambulatorial (DPCA): experiência de 15 anos em Curitiba. J Bras Nefrol. 1998;20(1):22-30.

5. Kim DK, Yoo TH, Ryu DR, Xu ZG, Kim HJ, Choi KH, et al. Changes in causative organisms and their antimicrobial susceptibilities in CAPD peritonitis: a single center's experience over one decade. Perit Dial Int. 2004;24(5):424-32.

6. Eisenberg ES, Ambalu M, Szylagi G, Aning V, Soeiro M. Colonization of skin and development of peritonitis due to coagulase-negative staphylococci in patients undergoing peritoneal dialysis. J Infect Dis. 1987;156(3):478-82.

7. Pereira ERPC, Gabriel DP, Lorençon M, Cruz AP. Análise retrospectiva de 92 episódios de peritonite em pacientes tratados por diálise peritoneal. $22^{\circ}$ Congresso Brasileiro de Nefrologia; 2004; Salvador, Brasil. São Paulo: Sociedade Brasileira de Nefrologia; 2004. p. 109-241.

8. Bannerman TL. Staphylococcus, Micrococcus, and other catalase-positive cocci that grow aerobically. In: Murray PR, Baron EJ, Jorgensen JH, Pfaller MA, Yolken $\mathrm{RH}$, editors. Manual of clinical microbiology. Washington: American Society Microbiology; 2003. p. 384-404.

9. Kwok AYC, Chow AW. Phylogenetic study of Staphylococcus and Micrococcus species based on partial hsp60 gene sequences. Int J Syst Evol Microbiol. 2003;53(1):87-92.

10. Sewell CM, Clarridge J, Lacke C, Weinman EJ, Young EJ. Staphylococcal nasal carriage and subsequent infection in peritoneal dialysis patients. J Am Med Assoc. 1982;248(12): 1493-5. 
11. Vandenberg MF, Verbrugh HA. Carriage of Staphylococcus aureus: epidemiology and clinical relevance. J Lab Clin Med. 1999;133(6):525-34.

12. Nouwen $J$, Boelens $H$, van Belkum $A$, Verbrugh $H$. Human factor in Staphylococcus aureus nasal carriage. Infect Immun. 2004;72(11):6685-8.

13. Nouwen JL, van Belkum A, Verbrugh HA. Determinants of Staphylococcus aureus nasal carriage. Neth J Med. 2001;59(3):126-33.

14. Pignatari A, Pfaller M, Hollis R, Sesso R, Leme I, Herwaldt L. Staphylococcus aureus colonization and infection in patients on continuous ambulatory peritoneal dialysis. J Clin Microbiol. 1990;28(9):1898-902.

15. Amato DMD, Ventura MJRN, Miranda GMD, Leaños BBSC, Alcántara GRN, Hurtado MEMD, et al. Staphylococcal peritonitis in continuous ambulatory peritoneal dialysis: colonization with identical strains at exit site, nose, and hands. Am J Kidney Dis. $2001 ; 37(1): 43-8$.

16. Nouwen JL, Fieren MWJA, Snijders SV, Verbrugh HA, van Belkum A. Persistent (not intermittent) nasal carriage of Staphylococcus aureus is the determinant of CPCrelated infections. Kidney Int. 2005;67(3):1084-92.

17. Piraino B. A review of Staphylococcus aureus exit-site and tunnel infections in peritoneal dialysis patients. Am J Kidney Dis. 1990;16(2):89-95.

18. Stinghen AE, Barretti P, Pecoits-Filho R. Factors contributing to the differences in peritonitis rates between centers and regions. Perit Dial Int. 2007;27 Suppl 2:S281-5. 19. Tzamaloukas AH. Peritonitis in peritoneal dialysis patients: an overview. Adv Renal Replace Ther. 1996;3(3):232-6.

20. al-Wali W, Baillod R, Brumfitt W, Hamilton-Miller JM. Differing prognostic significance of reinfection and relapse in CAPD peritonitis. Nephrol Dial Transplant. 1992;7(2):133-6.

21. Cunha MLRS, Caramori JC, Fioravante AM, Batalha JE, Montelli AC, Barretti P. Significance of slime as virulence factor in coagulase-negative Staphylococcus peritonitis in CAPD. Perit Dial Int. 2004;24(2):191-3.

22. Berns JS. Infection with antimicrobial-resistant microorganisms in dialysis patients. Semin Dial. 2003;16(1):30-7.

23. Koneman EW, Allen SD, Janda WM, Schreckenberger PC, Winn WC. Color atlas and textbook of diagnostic microbiology. 5th ed. Philadelphia: Lippincott; 1997. 
24. Cunha MLRS, Sinzato YK, Silveira LVA. Comparison of methods for the identification of coagulase-negative Staphylococcus. Mem Inst Oswaldo Cruz. 2004;99(8):855-60.

25. Clinical Laboratory Standards Institute. M100-S16, performance standards for antimicrobial disk susceptibility tests; approved standards. $9^{\text {th }}$ ed. Wayne, PA: CLSI; 2005.

26. Luzar MA, Coles GA, Faller B, Slingeneyer A, Dah GD, Briat C, et al. Staphylococcus aureus nasal carriage and infection in patients on continuous ambulatory peritoneal dialysis. N Engl J Med. 1990;322(8):505-9.

27. Zelenitsky S, Franczuk C, Fine A, Ariano R, Harding G. Antibiotic tolerance of peritoneal bacterial isolates in dialysis fluids. J Antimicrob Chemother. 2002;49(1):863-6. 